\title{
An Exploratory Study of the Interface Design Factors Affecting the User Intention to Use Mobile Applications
}

\author{
Wonjin Jung ${ }^{1}$ and Hyung Rok Yim ${ }^{2 *}$ \\ ${ }^{1}$ School of Business and Economics, Ankook University, South Korea \\ ${ }^{2}$ School of Business, Hanyang University, South Korea \\ 1jungw@dankook.ac.kr, ${ }^{2 *}$ hryim@hanyang.ac.kr
}

\begin{abstract}
Smartphones have evolved constantly since they debuted early in the 2000s. However, hardware features and the external environment restrict their use, making it difficult to ensure high interactivity. The structure and usage of smartphone applications are also becoming increasingly complex and it is often found to be difficult to understand their interface design. These user environments and conditions inhibit smooth user interaction with applications. This is expected to negatively affect user intentions to use mobile applications eventually. However, information systems research has not shown much interest in the effects of smartphone applications' interface designs on user attitudes and behaviors. Thus, this study attempted to explore the effects that application interface design has on user attitudes and behaviors when using mobile device applications. This study specifically focused on the following interface design factors: simplicity, consistency, and metaphors. Data was collected through a survey, and structural equation modeling (SEM) was employed for analysis. This study's results showed that these interface design factors have a significant effect on user interaction with smartphone applications as well as a positive effect on users'intention to use mobile applications.
\end{abstract}

Keywords: User interface, design, attributes, application, simplicity, consistency, interaction, intentions, users

\section{Introduction}

Smartphones, which are more than merely a communication tool, have become an essential part of modern life. Smartphones have become ingrained into our lives within a relatively short time largely because they offer a variety of applications that are beneficial in real life and can be easily installed for use anywhere, anytime. The type and number of the applications that have been developed for use are incalculably abundant and diverse; numerous applications are now constantly being developed and waiting for users to select them.

The reasons that users select and use certain applications vary between individual users. However, the most important reasons are usefulness and ease of use. Many studies in the field of information systems have regarded usefulness and ease of use as antecedents for user acceptance $[11,13,14]$. Furthermore, developers have tried to ensure that the applications they develop are useful and easy to use.

The quality of user-application interactions can be regarded as another reason that people select applications, along with the usefulness and ease of use of the applications. However, it is not easy to ensure high interactivity within the smartphone environment due to the restrictions that depend on the hardware features (e.g., the small display screen) and the external environment (for example, the brightness of the sun or ambient light).

Received (April 16, 2018), Review Result (June 7, 2018), Accepted (June 12, 2018)

* Corresponding Author 
Ultimately, these restrictions affect the use of smartphones [35].

Smartphone users mostly interact with their smartphones using their fingers. Because smartphones have a small screen, it is difficult for users with thicker fingers to accurately touch a specific location within the small display screen. It is difficult to design for a high interactivity of smartphones for this reason as well. Recently, the display screen size has grown because users tend to prefer a wide screen as well as enhancements, such as a stylus.

In addition, the small screen of smartphones doesn't provide sufficient space to contain lots of diverse information such as texts and graphics. Therefore, applications segment much diverse information and use features that help to locate them on several screens, or they reduce the size of text and graphics to contain them on one screen.

If too much diverse information and features are contained on the same screen, users may have to frequently scroll up and down, as well as left or right; simplicity and consistency are highly likely to be lost in the user interface (UI) design in such cases. Conversely, if information and features are deployed on several screens, the structure of the applications will become complicated due to the increase in the number of the screens and users are more likely to lose their sense of direction. Both of these issues may negatively affect how the user interacts with the application.

Furthermore, the small display screen of the smartphones will reduce the readability and discernibility of texts. In order to complement this, metaphors can be used in UIs. Metaphors are connotative messaging tools in the form of graphics instead of texts. However, this method may also affect the interaction between the user and the application. When exposed to the icons and buttons, menus that use metaphors that users find hard to understand result in users hesitating to use them. In order to resolve this problem, users have to exert a significant amount of cognitive effort and consequently suffer from mental fatigue and discomfort when using the interface. This may negatively affect the user's intention to use the application.

Recently, the structure and usage of mobile applications are becoming increasingly complex, and it is often difficult to understand certain UIs. These user environments and conditions inhibit a seamless user experience and are expected to eventually negatively affect the user's intention to use the applications. However, past studies on information systems have not shown much interest in the impact of UI designs of applications on the attitudes and behaviors of users in smartphone environments.

Thus, this study will attempt to empirically explore the impact that UI designs of applications have on the attitudes and intentions of the users utilizing these applications in smartphone environments. This research focuses on simplicity, consistency, and metaphors as the key attributes of UI design. Through this research, this study will provide practical recommendations for UI design. These recommendations will help to improve the interactions and usage intentions as well as to suggest the academic implications for associated research fields. Therefore, the study will contribute to the body of research in both theoretical and practical ways.

\section{Literature Review and Research Hypotheses}

\subsection{UI Design Attributes}

Interface is a system part. Users interact with systems [4] [36]. Moran (1981) argued that an interface usually has diverse physical and conceptual design components that provide system users with smooth interaction [41]. Interface designs vary. Accordingly, different interface designs differentially affect user interactions with systems.

Hypothesis 1: Simplicity in the user interfaces of smartphone applications positively affects user interaction with these mobile device applications.

Hypothesis 2: Consistency in smartphone applications' user interfaces positively affects 
user interaction with these mobile device applications.

Hypothesis 3: Metaphors used in the interfaces of smartphone applications positively affect user interactions with these mobile device applications.

Hypothesis 4: User interactions with mobile device applications positively affect mobile application users' attitudes towards these applications.

Hypothesis 5: Mobile application users' attitudes towards mobile applications positively affect mobile application users' intentions to use these applications.

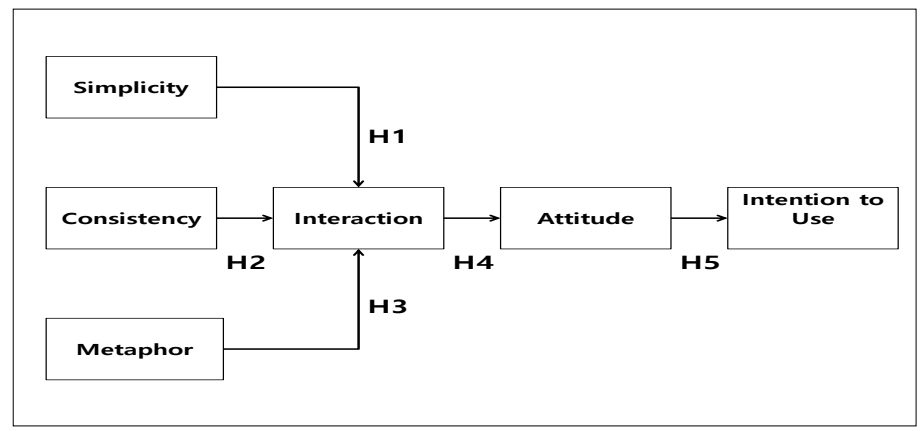

Figure 1. Proposed Research Model

\section{Research Methodology, Data Analysis, and Results}

This study explored the effects that mobile applications' user interface design attributes simplicity, consistency, and metaphors on the attitudes and behavioral intentions of the users. This was achieved by studying the interactions between the user and the application in the mobile device environment. In this study, these user interactions were considered as mediating variables. A survey was conducted to collect data and a total of 260 university students and practitioners volunteered to participate in the survey. One hundred and seventy-four students (66.9\% of the participants) answered the questions. The participants majored in economics, business administration, computer science, and graphic design at three universities in Korea. The gender ratio of the participants was $53.9 \%$ male to $46.1 \%$ female. The majority of the participants $(78.8 \%)$ were in their twenties. The application type that the participants used most frequently just before the survey was social networking and communications-related applications (61.9\%).

Table 1. Participant Characteristics

\begin{tabular}{c|c|c|c}
\hline \multirow{3}{*}{ Gender } & Characteristics & Frequency & Percent \\
\cline { 2 - 4 } & Males & 140 & 53.9 \\
& Females & 120 & 46.1 \\
\cline { 2 - 4 } Age & Total & 260 & 100 \\
\hline \multirow{5}{*}{ Job } & $20-29$ & 205 & 78.8 \\
& $30-39$ & 42 & 16.3 \\
& 40 Above & 13 & 5.0 \\
\cline { 2 - 4 } & Total & 174 & 100 \\
\hline Application & Students & 86 & 66.9 \\
\cline { 2 - 4 } & Practitioners & 260 & 33.1 \\
& Total & 161 & 100 \\
& Social Networking/Communication & 32 & 12.9 \\
& News/Internet/Browsing/Searching & 26 & 10.0 \\
& Games/Entertainment & 16 & 6.2 \\
& Maps/Navigation & 13 & 5.0 \\
& Mobile Banking/Finance/Shopping & 12 & 4.6 \\
\cline { 2 - 4 } & Utilities and other & 260 & 100 \\
\hline
\end{tabular}


Structural equation modeling (SEM) was employed to examine the proposed multivariate research model, and SPSS Statistics and AMOS ver. 18 were the statistical software used for the analysis. First, we tested the measurement model by examining the reliability of the individual survey items. In order to satisfy the reliability requirements, the loadings of all items on their respective constructs had to be above 0.6 or ideally $0.7[2]$. The results of analysis showed that all of the loadings were of 0.7 or higher, which meets the cutoff level of 0.6 (see Table 2). Therefore, the results suggest that the reliability is adequate.

Table 2. Standardized Regression Weights of Observable Variables, Composite Reliability (CR), and Average Variance Extracted (AVE)

\begin{tabular}{|c|c|c|c|c|}
\hline $\begin{array}{c}\text { Latent } \\
\text { Variables }\end{array}$ & Estimates & $\begin{array}{c}\text { Variance } \\
\text { C.R. }\end{array}$ & $\begin{array}{l}\text { Composite } \\
\text { Reliability }\end{array}$ & AVE \\
\hline \multirow[t]{3}{*}{ Simplicity } & .794 & 9.511 & \multirow[t]{3}{*}{.930} & \multirow[t]{3}{*}{.746} \\
\hline & .890 & 7.012 & & \\
\hline & .903 & 6.410 & & \\
\hline \multirow[t]{3}{*}{ Consistency } & .844 & 7.978 & \multirow[t]{3}{*}{.925} & \multirow[t]{3}{*}{.720} \\
\hline & .875 & 6.919 & & \\
\hline & .826 & 8.455 & & \\
\hline \multirow[t]{3}{*}{ Metaphor } & .831 & 8.722 & \multirow[t]{3}{*}{.933} & \multirow[t]{3}{*}{.749} \\
\hline & .874 & 7.465 & & \\
\hline & .890 & 6.799 & & \\
\hline \multirow[t]{3}{*}{ Interaction } & .866 & 7.511 & \multirow[t]{3}{*}{.894} & \multirow[t]{3}{*}{.710} \\
\hline & .820 & 8.718 & & \\
\hline & .842 & 8.233 & & \\
\hline \multirow[t]{3}{*}{ Attitude } & .897 & 7.287 & \multirow[t]{3}{*}{.936} & \multirow[t]{3}{*}{.786} \\
\hline & .901 & 7.093 & & \\
\hline & .860 & 8.597 & & \\
\hline \multirow[t]{3}{*}{ Intention to Use } & .908 & 5.576 & \multirow[t]{3}{*}{.911} & \multirow[t]{3}{*}{.724} \\
\hline & .883 & 6.757 & & \\
\hline & .754 & 9.822 & & \\
\hline
\end{tabular}

This study also examined the convergent and discriminant validity of the measurement model. The composite reliability (CR) and the average variance extracted (AVE) for the constructs were first analyzed to test the convergent validity. With respect to the values of CR and AVE, AMOS ver. 18 does not provide the functions to calculate the values, so they were manually calculated with the formulas, as suggested by Fornell and Larker [19] and Hair et al. [24]. The results of the analyses showed that the CR values of all constructs were greater than the recommended level of 0.7 (see Table 2). In addition, the results also showed that the values for the AVE of all constructs in the model were 0.7 or higher, which is well above the recommended level of 0.5 (see Table 2). Therefore, the measurement model demonstrated a satisfactory convergent validity.

$$
\begin{gathered}
\mathrm{CR}=\left(\sum \text { Standardized Regression Weights }\right)^{2} /\left(\left(\sum\right.\right. \text { Standardized } \\
\text { Regression Weights } \left.)^{2}+\left(\sum \text { Variance }\right)\right)
\end{gathered}
$$

$$
\mathrm{AVE}=\left(\sum \text { Standardized Regression Weights }{ }^{2}\right) / \mathrm{N}
$$

On the other hand, the discriminant validity for the measurement model was tested by comparing the square root of the AVE with the correlations among the constructs. The results of analyses for the discriminate validity showed that each construct had a square root of the AVE greater than the correlations between the construct and the other constructs (see Table 3). This indicates that the measurement model of this study satisfies 
the requirements of the discriminant validity.

Table 3. Correlation Coefficient Value between Constructs and AVE

\begin{tabular}{cccccccc}
\hline Constructs & AVE & $\phi^{2}$ & $\emptyset^{2}$ & $\phi^{2}$ & $\phi^{2}$ & $\phi^{2}$ & $\phi^{2}$ \\
\hline Simplicity & .746 & .318 & .257 & .477 & .401 & .423 & 1.000 \\
Consistency & .720 & .214 & .204 & .430 & .401 & 1.000 & \\
Metaphor & .749 & .299 & .287 & .416 & 1.000 & & \\
Interaction & .710 & .245 & .249 & .1000 & & & \\
Attitude & .786 & .477 & 1.000 & & & & \\
Intention to Use & .724 & 1.000 & & & & & \\
\hline
\end{tabular}

Next, the structural model was tested by examining the indices for the goodness of fit that include $x^{2} / \mathrm{df}$, GFI, AGFI, NFI, TLI, CFI, and RMSEA, and the results are as follows: $x^{2} / \mathrm{df}=2.712, \mathrm{GFI}=.874, \mathrm{AGFI}=.830, \mathrm{NFI}=.909, \mathrm{TLI}=.928, \mathrm{CFI}=.940$, and RMSEA $=.082$. Based upon the overall fit statistics, the proposed structural model can be considered to have a fairly good fit.

Finally, the path coefficients were examined to check the causal effects between the variables. To do so, the significance of the relationships between the variables in the proposed model was analyzed. As predicted in the hypotheses, simplicity had a significant influence on the interaction $(\beta=.396, \mathrm{p}<.0001)$, consistency also had a significant influence on the interaction $(\beta=.331, \mathrm{p}<.0001)$, and the metaphor was a significant determinant of the interaction $(\beta=.289, \mathrm{p}<.0001)$. In addition, the interaction had a positive impact on attitude $(\beta=.513, \mathrm{p}<.0001)$. Finally, attitude positively affected users' intentions to use the application $(\beta=.712, p<.0001)$. Thus, all of the hypotheses were supported. Table 4 shows the results of the test of the structural model and Figure 2 below also presents the results of the structural model analyses with $R^{2}$ values.

Table 4. Hypothesis Test

\begin{tabular}{llcccc}
\hline & \multicolumn{1}{c}{ Paths } & Coeff. & Stand. Coeff. & P & Results \\
\hline H1 & Simplicity -> Interaction & .396 & .377 & $* * *$ & Accept \\
H2 & Consistency -> Interaction & .331 & .258 & $* * *$ & Accept \\
H3 & Metaphor -> Interaction & .289 & .265 & $* * *$ & Accept \\
H4 & Interaction -> Attitude & .513 & .557 & $* * *$ & Accept \\
H5 & Attitude -> Intention to Use & .712 & .703 & $* * *$ & Accept \\
\hline
\end{tabular}

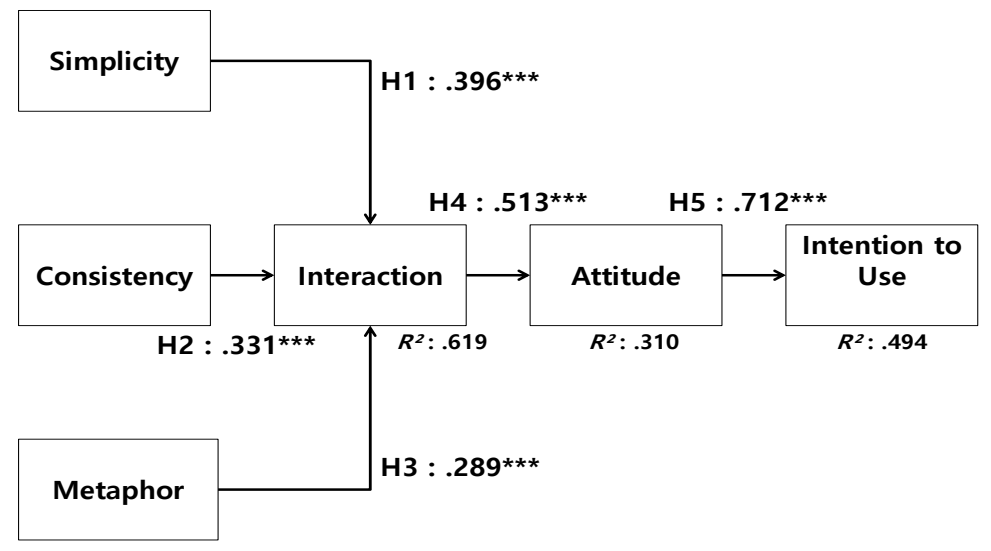

Figure 2. Structural Model Results 


\section{Discussion}

The study is meaningful in that it could identify the impacts of the interface design attributes on the user's intention to use the applications in smartphone environments and the role of the user-application interactions in the relationship. Many studies in the IS field in the past mostly examined the impacts of the interface design on the performance and use of the system through system qualities. However, not many studies have examined the direct impact of the simplicity, consistency, and metaphors as interface design attributes on user interaction. The study showed that causality exists between these attributes; so, these findings have contributed to the existing interaction-related studies by identifying the attributes of UI design that affect interaction.

In particular, studies of metaphors in the IS field have been limited. The findings of this study showed the importance of using the metaphors that can be understood by the users when designing the UI of a smartphone application. For the first time, the study highlighted metaphors as UI design components; as a result, this study differentiates itself from other studies. In addition, the study contributed to the relevant studies by emphasizing the importance of the metaphors in terms of the interactions by actually identifying the direct impacts of the metaphors on the interactions.

The study makes a valuable contribution to the body of research because it was conducted in the smartphone environment and not the PC environment. Personal computing environments in recent years are now gradually evolving into wearable devices beyond smartphones. Wearable devices, such as smart watches, require more efficient and seamless interactions than smartphones, but face more severe spatial constraints due to their smaller display screens. To resolve these limitations, UI designs that can make more intuitive understanding possible and that differ from PC-based information systems are required. The findings of the study indicate the direction in which UI design of wearable devices should precede.

Furthermore, this study identified the impacts of the interface design attributes on the attitudes and behavioral intentions of the users through the interactions. This means that the interactions with the applications and the user's attitudes and intentions for using the applications may alter depending on how the user perceives the UI design attributes. This does not only mean that the importance of the UI design and interactions were identified in explaining and understanding the factors affecting the user IT acceptance, but that it has also contributed to the extension of the model by adding new variables to TAM. Therefore, the study makes an academic contribution.

The practical contributions include having provided the consultations related to the designs necessary for the development of user-friendly UIs. The study shows that the improvements of the interactions with applications can be made through UI designs, especially simplicity, consistency, and metaphors. Therefore, to realize user-friendly UI, the design should be consistent and simple, and use metaphors that establish familiarity and help users understand the application. The findings of the study especially emphasize that developers should be considerate when introducing new metaphors in UI.

Another practical implication is that the study can be utilized in checking the simplicity, consistency and metaphors of the application UI designs. That is, the study makes practical implications; it enables the multidimensional assessment of applications in terms of aspects of their UI design. More specifically, it provides systematic assessment indicators and the tools necessary for checking UI design.

Finally, the findings of the study provide suggestions to promote the use of applications and improve sales revenue. Application designers who have considered UI design attributes when developing applications have improved the competitiveness of the applications; they have ensured high interactivity but also greatly increased sales revenue by securing large numbers of users who wanted to use the applications. The economic value and ripple effects that the developers can achieve are significant.

Despite some interesting findings, this study is subjected to the limitations of empirical 
research. For example, undergraduate students accounted for $66.7 \%$ of the participants and about $79 \%$ of the participants were in their twenties. Moreover, the diversity of the applications was not large. About $62 \%$ of the applications that the participants had used just before they answered the questions on the survey were social networking- and communication-related applications. These are areas of concern for external validity. Thus, follow-up research with large-scale testing is needed to address these limitations.

\section{Conclusion}

This study empirically explored mobile applications' interface design factors. These factors include simplicity, consistency, and metaphor. This study not only explored these factors but it also empirically examined that whether mobile application interface factors have effects on mobile application users' intention to use mobile applications through user interactions and user attitudes towards mobile applications. The analysis results of this study showed significant direct and indirect user interface factors' effects on user interaction with mobile applications. Furthermore, user interaction with mobile applications also had a positive impact on application users' intentions to use and their attitudes. These results addressed user interface design factors' importance for mobile applications. Especially these results are helpful to understand and explain the factors that affect user interaction with mobile applications and the intention to use them. In particular, this study emphasized how important it is for mobile applications to apply recognizable metaphors to mobile application user interface design. Practitioners can use these findings of this study to improve, not only the user interaction with mobile applications, but also application users' intention to use mobile applications when developing mobile applications.

\section{Acknowledgement}

This paper is a revised and expanded version of a paper entitled "An empirical study of relationship between User Interface Design Attributes in Smartphone Applications and the Intentions" presented at HSST, Hanbat National University in Korea, April 2018.

\section{References}

[1] A. D. Angeli, A. Sutcliffe and J. Hartmann, "Interaction, Usability, and Aesthetics: What Influences Users' Preferences?", in Proceedings of Designing Interactive Systems, New York, NY: ACM, (2006), pp. 272-280.

[2] D. Barclay, C. Higgins and R. Thompson, "The Partial Least Squares (PLS) Approach to Causal modeling: Personal Computer Adoption and Use as an Illustration", Technology Studies, vol. 2, (1995), pp. 285-324.

[3] M. Black, "More about Metaphor", Metaphor and Thought, Ortony, A.(ed.), Cambridge University Press, (1988).

[4] R. P. Bostrom, L. Olfman and M. K. Sein, "The Importance of Learning Style in End-User Training", MIS Quarterly, vol. 3, no. 1, (1990), pp. 101-119.

[5] J. Buzhardt, M. Abbott, C. Greenwood and Y. Tapia, "Usability Testing of the Class Wide Peer Tutoring-Learning Management System”, Journal of Special Education Technology, vol. 20, no. 1, (2005), pp. 19-29.

[6] V. Cantoni, M. Cellario and M. Porta, "Perspectives and Challenges in e-Learning; Towards Natural Interaction paradigms", Journal of Visual Languages and Computing, vol. 15, (2004), pp. 333-345.

[7] S. K. Card, T. P. Moran and A. Newell, "The psychology of Human-Computer Interaction", Hillsdale, NJ: Erlbaum, (1983).

[8] W. W. Chin, "The Partial Least Squares approach for structural equation modeling”, Marcoulides, G.A. (eds) Modern Methods for Business Research, Mahwah, NJ: Lawrence Erlbaum, (1998), pp. 295-336.

[9] C. Chou, "Interactivity and Interactive Functions in Web-based Learning Systems: A technical framework for designers", British Journal of Educational Technology, vol. 34, no. 3, (2003), pp. 265-279.

[10] C. Chu and B. K. Chan, "Evolution of Web Site Design: Implications for Medical Education on the Internet", Computer in Biology and Medicine, vol. 28, (1998), pp. 470-472.

[11] A. H. Crespo and I. R. del Bosque, "The Effect of Innovativeness on the Adoption of B2C e-Commerce: A model based on the Theory of Planed Behavior", Computers in Human Behavior, vol. 24, no. 6, (2008), 
pp. 2830-2847.

[12] G. H. Crowley, R. Leffel, D. Ramirez, J. L. Hart and T. S. Armstrong, "User Perceptions of the Library's Web Pages: A Focus Group Study at Texas A\&M University”, The Journal of Academic Librarianship, vol. 28, no. 4, (2002), pp. 205-210.

[13] F. Davis, "Perceived Usefulness, Perceived Ease of Use, and User Acceptance of Information Technology", MIS Quarterly, vol. 13, no. 3, (1989), pp. 319-339.

[14] F. Davis, R. Bagozzi and P. Warshaw, "User Acceptance of Computer Technology: A Comparison of Two Theoretical Models", Management Science, vol. 35, no. 8, (1989), pp. 982-1003.

[15] X, Fang, S. Chan, J. Brzeinski, and S. Xu, "Moderating Effects of Task Type on Wireless Technology Acceptance", Journal of Management Information Systems, vol. 22, no. 3, (2005), pp. 123-157.

[16] M. Fishbein and M. I. Ajzen, "Belief, Attitude, Iintention and Behavior: An Introduction to Theory and Research", MA: Addison-Wesley, (1975).

[17] M. Fishbein and I. Ajzen, "Understanding Attitude and Predicting Social Behavior", Prentice-Hall, Englewood Cliffs, NJ, (1980).

[18] J. Fong and I. Kwan, "Effective e-Learning by Using HCI and Interactivity on Data Modeling", International Journal of Computer Processing on Oriental Languages, vol. 16, no. 4, (2003), pp. 293-310.

[19] C. Fornell and D. F. Larcker, "Evaluating Structural Equation Models with Unobservable variables and Measurement error", Journal of Marketing Research, vol. 18, (1981), pp. 39-50.

[20] B. Gauss and L. Urbas, "Individual Differences in Navigation Between Sharable Content Objects- and Evaluation Study of a Learning Module Design", British Journal of Educational Technology, vol. 34, vo. 4, (2003), pp. 499-509.

[21] M. Gobe, "Emotional Branding: The new paradigm for connecting brands to people", New York, NY: Allworth Press, (2001).

[22] J. Grudin, "Consistency, Standards, and Formal Approaches to Interface Development and evaluation: A Note on Wiecha, Bennett, Boies, Gould, and Greene", ACM Transaction on Information Systems, vol. 10, no. 1, (1992), pp. 103-111.

[23] K. Gustafson, "The Impact of Technology on Learning”, Planning for Higher Education, vol. 32, (2004), pp. 37-43.

[24] J. F. Hair, B. Black, R. E. Babin, R. L. Andersong and Tatham, "Multi Variate Data Analysis", Upper Saddle River, NJ: Pearson Prentice Hall, (2006).

[25] J. Hartmann, "Assessing the Attractiveness of Interactive Systems," in Proceedings of the CHI 2006 Human Factors in Computing Systems, (2006), pp.1755-1758.

[26] J. Hartwick and H. Barki, "Explaning the Role of User participation in Information System Use", Management Science, vol. 40, no. 4, (1994), pp. 440-465.

[27] M. Hassenzahl and N. Tractinsky, User Experience: A Research Agenda", Behavior and Information Technology, vol. 25, (2006), pp. 91-97.

[28] M. Head, N. Archer and Y. Yuan, "World Wide Web Navigation Aid", International Journal of HumanComputer Studies, vol. 53, (2000), pp. 301-330.

[29] S. J. Hong and K.Y. Tam, "Understanding the Adoption of Multipurpose Information Appliances: The Case of Mobile Data Services”, Information Systems Research, vol. 117, no. 2, (2006), pp. 162-179.

[30] J. Johnson, T. L. Roberts, W. Verplank, D. C. Smith and C. H. Irby, "The Xerox Star: a Retrospective", IEEE Computing, vol. 22, no. 9, (1989), pp. 11-29. 